\title{
Flotation for the Practical Mill Man
}

\author{
A Description of Several Important Factors in Concentration by Flotation \\ By Frederick G. Moses, Salt Lake City, Utah
}

IT is a well known fact that the difficulties encountered in fiotation plants in different sections of the country are many and varied. While it is true that, in the great majority of -mills, the troubles are soon located and remedied, there are many other plants which are not so fortunate in the solution of their problems. It is usually found in the latter case that, although there is nothing apparently wrong with the mill or its operation, the results being obtained are not so good as the experimental work on the ore had led the builders to believe could be obtained. Because a profit is being made, the idea of leaving well enough alone often leads the operators into the state of mind in which they are satisfied to make the best of a bad situation and to be content with the results that they can get.

There are some cases in which the mill results are not satisfactory and, moreover, cannot be readily improved. This is, however, seldom the case. More often the poor results are caused by some condition, often a simple one, that can easily be remedied, if located. Unfortunately, there is such a multiplicity of conditions, any one of which can cause poor flotation results, that it is hopeless for the average mill operator to investigate more than a comparatively few possibilities.

It will be the object of this discussion to suggest some of the factors affecting flotation results, and to suggest ways in which some of them may be overcome. Of course, it will be possible to consider only a limited number of the conditions that work for poor flotation results. There is always the chance, however, that a discussion of some of the more common difficulties encountered in flotation plants will suggest the
manner by which some specific or unusual source of manner by which some specific or unusual

FLotation a concentration pRocess.

It is imperative that the fact that flotation is a concentration process, as much as any gravity scheme, be borne in mind. If this fact is remembered when considering any phase of flotation, the solution of the problems connected with its operation will be considerably simplified.

As flotation is a concentration process, it must follow that the economic laws of concentration will apply to it as much as to the gravity concentrator. In every case of concentration there is a maximum extraction and grade of concentrate possible. This theoretical result can be approached in the commercial installation, but never. reached. Usually the greatest obstructions in the way of obtaining scientific results are the economical considerations that surround the mill operator on all sides. The plant must be run to make the greatest profits, and attempts to obtain better metallurgica results will often serve only to reduce the profits.

It must also be borne in mind that, like a table, the capacity of a flotation machine is limited. Notwithstanding the fact that the maximum capactty is bur seldom reached, there is always the possibility that this be done, to the detriment of the results obtained on the machines. If the operator takes care that the apparatus is not overloaded, he has eliminated many of the chances for poor work in his plant.

The crushing of flotation feed is as important to good flotation results as the crushing of table feed is important to good table work. The sizes that can be floated are limited to a fewer number than can be tabled successfully, and poor sizing or classification of flotation feed can cause even more unsatisfactory results than in gravity machines. The ore must, of necessity, be crushed fine enough to free the maximum quantity of mineral, but with the production of the minimum amount of slime or very fine material. The slimes, especially the true colloidal material, will be found to be more often the cause of poor flotation than any other factor that will be encountered in the plant.

EXTRACTION AND GRADE OF CONCENTRATE.

The metallurgical and economical success of the flotation plant depends on the recovery of the greatest amount of the valuable mineral from the ore in the purest possible concentrate. Just what are the economical limits of extraction and grade of concentrates depends on local conditions and must be determined for each mill; in the present discussion, they will be considered to be the best metallurgical results allowable

${ }^{*}$ Reprinted from Chem. Metall. Engineering. under the conditions existing in the locality of the mill. As already suggested, each ore has a maximum and definite ratio of concentration, and hence there is maximum grade of concentrate possible. The maximum extraction is, of course, 100 per cent. of the values in the ore, a figure that can only be approached. The important fact to be remembered in this connection is that in the flotation plant, as in the gravity mill, recovery can be increased only at the expense of grade
of concentrate, and vice versa. The flotation operators who remember this fact will save themselves much trouble and worry that always follow attempts mad to obtain scientifically impossible results. Unfortunately, so few plants are approaching theoretical re sults that their consideration can be eliminated from the present discussion.

\section{FLOTATION RECOVERIES}

Ignoring, for the present, the consideration of grad of concentrate, it can be said that extraction by flotation depends on many factors, among the most im portant of which are: (1) The physical condition of the ore being treated, (2) the flow sheet of the mill, and (3) the effectiveness of the flotation operation. While the first two are not so important as the last they are so often the cause of flotation difficulties that they should be considered.

At the present time, the mineral values that occur in the ore as sulphides are all that can be depended upon to be recovered by flotation. When only nonoxidized sulphides are present, it should be possible, theoretically, to obtain high metallic extractions. How ever, when such easily oxidized material as iron sulphide is present and carries values, as often happens, trouble in obtaining good recoveries may be encountered. There have been put on record cases in which this material, by simply lying in the ore bins for short time, has undergone enough oxidization to make the flotation of the iron sulphides very difficult. The remedy, of course, for a condition of this sort is to mil the mater

The size of the sulphide particles occurring in the ore greatly affects the possible recovery from an ore. When this sulphide reaches the flotation machines in very coarse sizes it will not float. Unfortunately, on the other hand, when the sulphide particles have been ground too fine, or "slimed," they can be floated only with difficulty. In most cases it will be found that the greatest loss in the tailings from a flotation plant is in the minus 200-mesh material. Proper crushing pre vious to flotation will correct these conditions to a vious to flotation will correct these conditions to a
great extent. However, the actual size and condition of the sulphide, as it occurs in the ore, will be a ver dominant factor.

All ores carrying decomposed or kaolinized minerals re difficult to float. This physical condition will probably have more effect on the actual flotation operation and its results than any other single thing that could be mentioned, and at the same time it is the most difficult to overcome. Why clay and other colloidal material have such harmful effects is difficult, at best, to explain on a scientific basis. A discussion of thi point will delve so deeply into the pure theory of flotation as to be out of place in this consideration. Instead, a few suggestions about means of eliminating or trolling this material will be more to the point.

There may be said to be two general schemes by which the detrimental effect of slime may be overcome The first and most important is by flocculation or pre cipitation by chemical or electrochemical schemes. The second and least used method is that of washing. Heating of the ore before crushing is sometimes trier. Rather than give a long scientific definition of just what colloidal material is, it will be better to give a very simple method of determining the presence an amount of this material. Colloidal material, or mor commonly "slime," can be best detected and its quạn tity estimated by the slowness with which it will settl in water. A rough application of this scheme can be made by taking a portion of the flotation pulp and shaking it thoroughly in a bottle. If there is any quantity of colloids or slime present the water will this cloudy appearance persists for half an hour there is probably sufficient slime present in the pulp to inis probably sufficient

The amount of the slime that may be present may be roughly estimated by the depth of clear water that appears on top of the pulp in a given time. Of course, is all that would be required except in special cases.

$$
\text { REMOVAL OF SLIME. }
$$

Some simple chem'ical compounds, under certain definite but usually little understood conditions, have the property of causing the suspended or deflocculated slime in the pulp to collect together, or flocculate, changing the physical conditions in such a way that rapid settling occurs. It has been found by experiment that slime in this condition usually has very much less harmful effects on flotation than when deflocculated. Sulphuric acid, lime sodium carbonate, acid sodium sulphate, copper sulphate and many other substances, when used in very small amounts, have the property, under certain conditions, of flocculating the slimes. In this way their harmful effects are very largely removed.

At the present stage of our knowledge of this phase of flotation, it is practically impossible to foretell which of the numerous reagents that have been used for this purpose will give the required results on a particular ore. The most effective one can only be determined by experiment under the conditions under which it is to be used. The reason for this is our lack of knowledge of the real manner in which they act on the slimes in the ore.

The ideal manner of ascertaining the reagent to be used is by direct experimentation in the commercial cells of the operating plant. If, for any reason, this is not feasible, indicative results can sometimes be obtained by a series of tests made in bottles. Several samples of the pulp from the flotation machines, containing the oils being used, are placed in a series of bottles and well shaken. Two or three drops from solutions of the various reagents are then added to the bottles, a separate bottle being used for testing any one solution. The bottles are then placed where they will be free from vibration for an hour or more. It will be seen, at the end of this period, that some of the bottles have a certain volume of clear water above the cloudy pulp and that, in certain cases, this volume will vary widely. It is usually the case that the reagent showing the greatest settling effect will produce the best results when used in the cells. However, this is not always the case.

The removal of slimes or colloids by washing is a more difficult matter, requiring quite an installation of settling tanks or thickeners, and a comparatively large supply of fresh, pure water. This last item is of the utmost importance. The actual operation of the scheme is quite simple. The pulp, before being fioated, is settled in the thickening tanks, which are so operated as to give the thickest spigot product possible, without allowing the overfiow to carry away an excessive am al of valuable mineral. The overlow, which carries a large portion of the slime material, is allowed to run to waste, and the thick spigot product is diluted with sufficient clean, fresh water to give the correct pulp density for flotation. This method has worked well in several large plants in the West.

Another scheme which might be used, but which for various practical and economical drawbacks has received but scant attention, involves heating the ore before crushing to a temperature great enough to put the slime-forming material in the ore into such a physical condition that slime formation is retarded when the ore is wetted and crushed.

There are many materials foreign to the ore, such as decomposed vegetable matter, lubricating oils from line shafts or crusher bearings, soap, sewage, grease from mine-car wheels, etc., that will interfere greatly with flotation. The only sensible remedy for this type of trouble is to eliminate the source of it. Great care must be taken to prevent these substances from getting into the flotation feed. The great difficulty often encountered in finding the source of this sort of interference makes it imperative that care be used to eliminate it.

MILL FLOW SHEETS AND THEIR EFFECTS

Sometimes it does not seem possible that such a simple matter as the location of a table in a flotation mill could make any great difference in the results obtained. Nevertheless this has often been proved to be the case. 
It is as necessary that the flowsheet of a plant using flotation be as carefully worked out by experiment as when gravity processes only-are to be used. Many when gravity processes only - are to be used. Many flotation plants can be shown
work for this reason alone.

work for this reason alone.
In many instances, the ore should be tabled previous to flotation in order to remove the heavy sulphides which are present but which cannot be floated. These will only tend to build up in the machines, choking up the cells and preventing their efficient operation. Also it is sometimes possible so to remove from the pulp certain deleterious substances, such as slimes.

In certain cases the best results demand that the pulp be tabled after flotation. A great tendency in many flotation plants is to carry too dilute pulp in the flotation apparatus. Tabling before flotation is boun to add water to the flotation feed and this causes poo operation. Tabling following flotation has not this drawback.

The use of pilots by which the work of the flotation machines can be judged should not be overlooked in this connection. The flotation operators can soon be taught from the appearance of the tables treating the flotation tailings whether the cells are doing good, ba or indifferent work. They thus have an optical demonstration of what their part of the general scheme is ac complishing, and this will always work toward securing better results from the flotation machines.

Before leaving the discussion of mill flowsheets and their bearing on flotation results, the effects of variou types of crushing on flotation results should be mentioned. This is one of the things that is without th pale of help from the operator, but some valuable sug gestions may be evidenced by the consideration.

There is no doubt that the type of crushing to whic the ore has been subjected before flotation will have a noticeable effect on the results obtained. The wellknown case of the Inspiration mill, where a better re sult was obtained by crushing with iron on iron than by pebbles on iron, is an example of what a difference such a simple point can make.

The fact that the type of crushing which produce a large amount of slime is not as satisfactory as that which will produce the minimum quantity has been already suggested. A certain plant in Arizona is divided into two units, exactly alike, except for different types of crushing maclines employed in them. The ore, flotation equipment and other factors are the same. The extractions obtained in the two units always varied to a certain extent, and the difference in th varied to a certain extent, and the difference in the
crushing was the only explanation that could be offered crushing was the only explanation that could

as the reason for this peculiar behavior.

of the sulphide content of an ore that is too fine for satisfactory gravity work. It can never be made to replace tables satisfactorily, except under an unusual combination of circumstances. Stage crushing, there fore, with the removal of the mineral as soon as it fore, with the removal of the mineral as soon as it is
freed, followed by flotation of the sulphides that have been crushed too finely for table work, in genera seems to be the best and most logical scheme, and should be followed whenever possible.

\section{EFFECTIVENESS OF FLOTATION OPERATION.}

The points already discussed have been mentione because of their indirect effect on flotation. There are also, certain factors in the operation of the flotation equipment itself that are of even more importance to equipment itself that are of even more importance
good flotation results than those already mentioned.

good flotation results than those already mentioned.
One of the most important factors in good flotatio is the oils or combinations of oils that are being used. If all of the other conditions are perfect with the exception of the oil, good flotation results are impossible. Unfortunately, the investigation of oils cover such a large field and depends on so many little understood or unknown factors, that no definite rules for stood or unknown factors, that no definite rules
determining the most satisfactory oil can be given.

determining the most satisfactory oil can be given.
As long as the art of flotation has been practiced, the only feasible method of determining the oil best adapted for an ore has been by laboratory or mill exper ments. This method of investigation involves much time, patience and money, but the. importance of the information gained always justifies the expenditure. The operator should never reach the state of mind The operator should never reach the state of mind
that permits him to be satisfied with the oil he is em that permits him to be satisfied with the oil he is em
ploying. He should test all of the logical mixture available, and as new oils come on the market, the should, also, be given their chance.

The agitation to which the oil and pulp have been subjected is the next important factor in good flotation results. This must be correct, both with regard to kind and amount. The lack of sufficient agitation is usually evident at once, but too much is more difficult to recognize and is just as harmful as the opposite to recognize and
state of affairs.

Too much agitation will do one of two things: either produce too much froth, usually of an unsatisfactory character, or cause the oils to be so thoroughly emulsified as to destroy much of their flotation value. It is very probable that the principal function of much of the acid used in flotation is to throw oils out of emulsion that have received too much agitation in the ore pulp.

If the mechanical agitator type of machine is not designed correctly for the ore which it is to treat, it will either produce too much froth or too little. Either of these conditions will tend to cause poor recovery. When the ratio of the size of the agitator and its speed is correct, or that of the agitator compartment to the froth tank or spitzkasten, the quantity of froth proluced by the use of the right amount of oil will be wrong. In such a case, the common method of attempting to rectify conditions is by changing the amount of oil used. This is unsatisfactory in most cases.

If too little froth is being made by the machine by the use of the correct amount of oil, air blown into the pulp at the bottom of the spitzkasten will often correct matters very satisfactorily.

The troubles caused by the production of too much froth when the correct amount of oil is being used are much more difficult to rectify. The greatest chance for mprovement, under these conditions, is to increase the tonnage to the machine, although other factors may cause this scheme to fail.

Over-oiling the flotation pulp will usually be indicated by the occurrence of large amounts of mineralbearing froth in the launders carrying the tailings from the machines, or on the tables or other apparatus that may be used to re-treat the flotation tailings.

\section{MPORTANCE OF PURE WATER}

One of the greatest necessities for good flotation work is a large and constant supply of fresh and pure water. It is considered good flotation practice to settle the water from the flotation tailings for re-use in the flotation circuit, in order to obtain the benefit of the oils that will be returned to the mill in this manner. This is logical and works very well, rvithin certain limits. A point that must at the san time be considered is that the soluble constituents of the ore or oils will gradually be concentrated in this return water and will eventually attain an accumulation that will interfere very materially with the operation of the flotation machines. For this reason, increasing the amount of fresh water that is being added to the flotation circuit will often work wonders in the way of improving flotation results. This fact is very easily determined and the test should be made at frequent and regular intervals.

Often the fresh water supply of the mill will carry certain unsuspected impurities in solution. These impurities may be either harmful or beneficial. The preponderance of chances are, however, that they will interfere with the proper operation of the cells. For tunately, most of the inorganic salts that occur in this way can be very easily and cheaply removed by simple chemical precipitation. Many cases have been known where the flotation plant had been built on the strength of a large amount of successful experimental work, but no successful results could be obtained until by chemical analysis of the water used in the mill circuits the presence of large amounts of inorganic salts in solution had been demonstrated. When this material had been removed by the use of lime or some other necessary reagent the mill at once commenced to produce the results that had been expected when the plant was completed.

Organic material, such as soaps, glues, decomposed vegetable matter, organic soil constituents, etc., will cause more harm in the flotation plant than the inorganic salts just mentioned. Their removal is a much more difficult proposition. If their presence can be more difficult proposition. If their presence can be
proved to be the cause of trouble, it would be better to employ special talent to handle the situation rather
than to allow inexperienced men to try their hand.

TIME FACTOR AND FLOTATION RESULTS.

The period of time during which the ore pulp is under treatment in a flotation machine is a most impor tant factor of good flotation results. Flotation is by no means an instantaneous process. A certain definite time is required to remove the concentrate from the ore pulp. The amount of time required for this purpose depends on several important considerations, among which may be mentioned (1) the amount of pulp, in gallons, which is being treated in the flotation apparatus per minute, (2) the solid content of the pulp volume being treated, (3) the number of pounds of concentrate that must be removed from each gallon of the pulp, (4) the strength or carrying power of the froth being made on the machine, and (5) the quantity of froth being made per unit time.
It will be evident that, other things being equal, the more dilute the pulp the greater will be the velocity with which each unit of ore in the pulp will pass through the machine. Hence, to obtain the same time of treatment on the more dilute pulp will require a greater comparative length of time of treatment in the machine. When dealing with pulp dilution, however, many other factors enter into consideration and the above can only be taken as a generality.

On the other hand, a pulp must not be too dense, or the bubbles cannot rise freely to the surface. When the pulp is too dense there is the added chance that the bubbles will be scoured clean of their mineral load. the correct pulp density to fit the conditions of the case can only be determined definitely under practical operating conditions.

A froth has a certain maximum carrying power. When it is made at a definite rate per minute it can more pounds of concentrate are contained in the pulp fed to the machine than can be removed by this froth, poor extraction of the sulphide in the ore is bound to result. When the poor recovery in the flotation machines can be definitely laid to this condition, the remedy is either to feed a smaller volume of pulp to the apparatus, to make more froth of the same character or, by means of different oils, to increase the carrying power of the froth being produced. The most satisfactory method of remedying the difficulty must depend on the ore and the other local conditions existing in the plant. These points are all matters of experiment and skill of operation.

RELATION OF GRADE OF CONCENTRATE TO EXTRACTION.

In all ore-dressing and concentration processes, the grade of concentrate produced has a most important
relation to the possible extraction. A few of the more important reasons why this is especially true in flotation will be mentioned.

An observation of the froth forming on the top of the pulp in a flotation machine will clearly show that a great deal of the concentration that takes place in the machines takes place in the froth. The froth nearest to the pulp will be practically the color of the pulp, but the closer the top the froth is observed, the more nearly its color approaches that of the pure mineral that is being floated.

This effect is caused by a mechanical action that goes on within the body of the froth itself. The bubbles seem to have only a comparatively weak selective action on the sulphides in the pulp itself. This condition causes the froth, first released at the bottom of the froth column, to carry a very large amount of gangue material. As soon as the froth is out of the water, however, it commences to break up, the bubbles first formed breaking up to reform a slightly fewer number of new bubbles. During this process of reformation, the sulphides are caught on the newer bubbles formed, while the gangue is, to a large extent, forced to drop back into the pulp owing to the decreased froth surface. This action goes on from the bottom to the top of the froth column, causing the froth the greatest distance from the pulp itself to be the highest in grade.

It can be seen from this that the deeper the froth column carried on top of the pulp in the flotation machine, the higher is the grade of concentrates produced and the greater is the amount of gangue dropped from the froth into the pulp, at the same time, however, the greater is the chance for the sulphide particles to be dropped into the pulp and lost in the tailings, causing a lowered extraction.

This shows the reason for the relation between the grade of concentrate produced and the extraction possible, and, also, the principal reason for the use of one set of machines for producing the best tailing possible, and the use of another set of apparatus for recleaning the froth produced on the first machines.

\section{PRODUCING CLEAN CONCENTRATES.}

At the first of this discussion, the fact was mentioned that, in order for a plant to be successful from both a metallurgic and an economic standpoint, a good extraction of the values in the ore must be obtair

a high grade concentrate must be produced.

The concentrate is the material that must be sold to produce the income from the milling operation. The greater the amount of valuable metal present, the more can be obtained for it, while the smaller the amount of impurities present, the fewer the penalties imposed by the buyer and the less charged for their treatment. All these considerations make it imperative to produce the highest grade concentrate economically possible.

The grade of flotation concentrates produced will depend on several factors, among which can be mentioned (Continued on page 48) 


\section{Flotation for the Practical Mill Man} (Continued from page 35)

(1) the natural amenability of the ore to the process (2) the simplicity of the sulphide content of the ore being treated, (3) the sort of results that the flotation equipment is being operated to obtain, and (4) the skill and care with which cleaning the concentrates is done.

The flrst two of these factors are, to a great extent, beyond the control of the operators. However, tỳe second two are of such a nature that they can be much influenced and controlled by the operators.

NATURAL AMENABILITY OF ORE TO FLOTATION.

It as been often found that two ores, apparently of the same physical and chemical makeup, respond very differently to flotation, the one giving maximum re sults without trouble, while the other can only be treated satisfactorily with the greatest difficulty. Just why this is true is often very difficult to explain

It is, however, usually easy to obtain both high grade concentrates and high extractions when treating the ores that respond easily to flotation, the probable reason being that when dealing with this type of ores, a small amount of the lighter pils will give high recoveries of the sulphides present, and, at the same time, this type of oiling will in nearly all cases produce the this type of oiling will
richest concentrates.

When dealing with the other ores-those which can only be made to respond to flotation treatment with difficulty-it is usually necessary, in order to obtain high recoveries of the sulphides, to use a comparatively large amount of heavy flotation oils. This class of oils will, it is true, make high recoveries, but in so doing often float such large amounts of gangue as doing often float such large amounts of gangue
always to cause the concentrate to be low grade.

As suggested, these factors usually depend more on the ore itself than on any of the conditions that can be controlled. However, from the above it can be seen that when the ore is readily amenable to flotation, both high recoveries and rich concentrates can be produce by the same operation, but when the ore does not respond readily, high recoveries can be obtained with greater ease than high grade concentrates, and neither can be gotten at the same time.

In an ore composed of simple gangue minerals and only one flotable mineral, it is easy to see that the chance of producing high grade concentrate is greater than when two or more minerals that float are present.

\section{COMPLEXITY OF SULPHIDES AND GRADE.}

When several sulphides, such as lead, zine and iron sulphide, for instance, are present in the ore, there are two possible schemes that might be used in overcoming the tendency for the production of, say, a low grade zinc concentrate. The success of either of these will depend largely on the character of the ore and its sulphide constituents. One of these methods involve the removal of one or more of the sulphides by gravity before the flotation of the ore for the recovery of the other-sulphide. The other scheme depents on a dif other-sulphide. The other scheme depends on a dif
ferential or selective flotation operation to recover one of the sulphides without removing the other two. This has been done to a limited extent in various sections of the country, but at best it is a very delicate operation and will require large amounts of experimental work; careful control of the flotation operations themselves, knowledge of the relations of the various minerals to one another and, above all, great skill in the erals to one another and, above all
actual operation of the equipment.

There is no question that the grade of the flotation concentrates can be influenced greatly by some such schemes as those mentioned, but their success is bound to be limited. They are really special cases of flotation and should not be discussed here.

FLOTATION OPERATION AND GRADE OF CONCENTRATES.

Probably the greatest factor affecting the grade of the product is the manner in which the machines them selves are run from shift to shift. The grade of the concentrates will depend largely on (1) whether the machines are being operated to obtain the maximum re covery or the maximum grade of product, '(2) on the skill and intelligence with which the oils are used skill and intelligence with which the oils are used
(3) on the skill and care with which the pulp level and (3) on the skill and care with which the pulp level and
depth of froth on the machines are controlled, and (4) on the pulp density.

The effect of the first point mentioned, the result that are being striven for on the machines, has been suggested already. Much of the concentration takès place in the froth column, and when the froth is al lowed to discharge from the apparatus so slowly that most of the gangue has had time to drop from it, some of the mineral will also be dropped into the cells, causing a lowering in the recovery, but at the same time the maximum grade of product will result. Just the point at which these two conditions should be balanced is an economic matter and can only be worked out on the profit sheet of the mill.

The fact should be emphasized at this point that beyond a certain point the grade of concentrate can only be better at the expense of recovery, and vice versa. This will be the dominating thought that will be carried through any discussion involving extractions and grade of concentrates by flotation processes, or any other process, for that matter.

\section{OIL AND GRADE OF CONCENTRATES.}

The necessity for the intelligent use of flotation oils and reagents to obtain the highest grade of product from a flotation machine has also been suggester in from a flotation machine has also been suggester in another connection, and should be fairly evident. The
strength and carrying power of the froth will depent largely on the kind and amount of oil used in the circuit. The grade of the concentrate also depents very largely on the same factors. If a weak froth man be made which will carry sufficient sulphide to give a high recovery, this froth, from its very nature, will not be prone to carry much of the gangue.

If a froth of a strong, stiff character is required to give high extractions, it will tend to carry much more gangue material and hence produce a lower grade of gangue material and hence produce a lower grade of
concentrate. As the oils are the dominating factor on which the strength and carrying power of the froth depend, the evident relation of the oils to the mineral purity of the concentrate should be clear.

Of course, the ideal practical condition will be to use the oil mixture that will prevent the flotation of the gangue to the greatest extent, and yet float all of the gangue to the greatest extent, and yet float all of the tion the highest recovery will be possible, and the concentrate produced will be ideal for cleaning in the cleaner cells.

$$
\text { PITIP LEVEL OR DEPTH OF FROTH. }
$$

The relatin -6 the level of the pulp and the depth of froth to the giade of the concentrates was suggested in connection with the remárks on extraction. Slowly discharging froth and deep pulp level mean a long period of time for the contration in the froth column to take place, with the dropping out of a correspondingly large amount of impurities from the froth.

The operators can soon learn, under the different ditions that will be encountered, the correct depth of pulp to obtain the highest extraction and, at the same time, the maximum grade of concentrates. The pulp level will depend to a certain extent also on the quality of sulphides in the pulp fed to the machine.

As a general rule the larger the amount of sulphide that must be removed from the machine, the higher the pulp level will be carried, and the faster the froth will be discharged. The operators soon learn to judge these conditions, and make the necessary adjustments when they are required.

\section{PULP DENSITY. AND GRADE OF CONCENTRATES.}

The reasons for the variations in the pulp density upon the grade of concentrates are a little more difficult to understand. The ratio of water to solid in a flotation machine has much to do with the character of the froth the machine is producing. Just why this should be true is hard to say.

It has been previously shown that the character of the froth affects the grade of concentrate. Now froth characteristics will continue to have the same effect on the purity of the concentrate, regardless of whether they can be traced to under- or over-oiling of the pulp, or by thickening or diluting it, as in the case now under discussion.

There is yet another manner in which the pulp density may affect the purity of the concentrate. It is the effect of the pulp density on the amount of sulphide that will be carried into the machine in a certain time.

A flotation machine can produce a given amount of froth of certain characteristics in a given period of time: If a dilute pulp is being fed to the machine there will be fewer pounds of sulphide to be removed by this amount of froth; a condition that, due to its unsaturated condition, will increase the chances of the froth picking up the gangue material, and therefore lowering the purity of the concentrates.

As would be expected, increasing the pulp density will tend to have the opposite effect on the grade of concentrates. In this case, there is an increase in the amount of mineral to be floated by the available froth, causing it to become quickly saturated with sulphide and so leaving but little space for the gangue material. This result is probably brought about by the fact that the sulphides are the easiest to float and will have the greatest tendency to be attracted to the froth and held there, in preference to the non-sulphide material. Thi condition in the machine will also tend to increase the concentrate grade, but at the same time lower the extraction.

(To be continued.)

\section{SCIENTIFIC AMERICAN SUPPLEMENT \\ Founded 1876}

Published by Scientific American Publishing Co.

New York, Saturday, July 19, 1919

Mann \& Co., 233 Broadway, New York

Charles Allen Munn, President: $\quad$ Orson D. Munn, Treasurer Allan C. Hofman, Secretary, all at 233 Broadway

The Scientific American Publication Sclentlfic American Supplement (establlshed 1876) por. year 85.00
Sclentific American (established 1845). The combined subscription rates and rates to foreign countries. Includlng Canada, will be furnished upon application.

Scientific American Publishing Co. 233 Broadway, New York

The purpose of the Supplement is to publish the more important announcements of distinguished technologists, to digest significant articles that appear in European publications, and altogether to reflect the most advanced thought in science and industry throughout the world.

Back Numbers of the Scientific American Supplement

SUPPLEMENTs bearing a date earlier than January 1st, 1918, can be supplied by the $\mathrm{H}$. W. Wilson Company, 958-964 University Ave., Bronx, New York, N. Y. Please order such back numbers from the Wilson Company. Supplements for January 1st, 1918, and subsequent issues can be supplied at 10 cents each by Scientific Amierican Publishing Co., 233 Broadway, New York.

We wish to call attention to the fact that we are in a position to render competent services in every branch of patent or trade-mark work. Our staff is composed of mechanical, electrical and chemical experts, thoroughly trained to prepare and prosecute all patent applications, irrespective of the complex nature of the subject matter involved, or of the specialized, technical, or scientific knowledge required therefor.

We also have associates throughout the world, who assist in the prosecution of patent and trade-mark applications filed in all countries foreign to the United States.

Branch Office:

625 F Street, N. W.

MUNn \& Co.,

Washington, D.

232 Broadway,

Work, N. Y.

\section{Table of Cont}

Flotation for the Practical Mill Man.-Ay F. O. Moses... 34 "Cupping" vs. "Boxing."-By C. H. Herty-Illustrated... 36
Acquired Radioar"
Sir W F"nokes-Concluded. 39 Recent Develor.

French and Germa

Hull Form for High

Meth ods of Etching
istics of Rail Steel

istics of Rail Steel
ingest and Most Durable

Concluded

Siags
rostructure and Disintegration
Rich in Lime $\ldots \ldots \ldots \ldots \ldots \ldots \ldots \ldots \ldots \ldots \ldots$

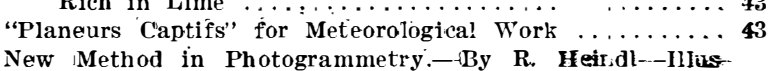

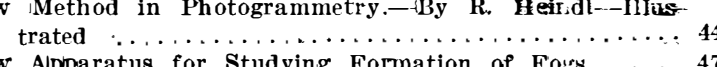

New Apparatus for Studying Formation of Fogs ..... 47
Protection of Iron Against Rusting $\ldots \ldots \ldots \ldots \ldots \ldots$ 